\title{
Codependency Among Family Members as Predicted by Family Functioning and Personality Type
}

\author{
Myrtle C. Orbon ${ }^{1}$ Debora Basaria ${ }^{2}$ Francisca Iriani R. Dewi ${ }^{2}$ \\ Mylene S. Gumarao ${ }^{1}$ Vicky C. Mergal ${ }^{1}$ Pamela Hendra Heng ${ }^{2 *}$ \\ ${ }^{1}$ Adventist University of the Philippines, Puting Kahoy, Silang, Cavite, Philippines \\ ${ }^{2}$ Faculty of Psychology, Universitas Tarumanagara, Jakarta, Indonesia \\ *Corresponding author. Email: pamelah@fpsi.untar.ac.id
}

\begin{abstract}
Substance-use problems affect not just the residents in the treatment facility but the whole family system. The present study considered the family members of the residents in treatment and rehabilitation as the respondents of the study. Specifically, the study looked into the family functioning, personality type, and codependency. Codependency was measured in terms of self-sacrifice, reactivity, and external focus. Problem-solving skills, goal setting, and communication skills were used as measures of family functioning. Moreover, personality type was measured in terms of openness to experience, conscientiousness, extraversion, agreeableness, and neuroticism. There were 302 respondents in the study from different public and private treatment and rehabilitation facilities in Luzon, Visayas, and Mindanao. The result shows that problem-solving skills predict self-sacrifice with $13.6 \%$ of variance accounted for. In addition, higher level of neuroticism predicts low level of reactivity or willingness to solve their family problems and that goal setting predicts external focus. The study implies that one's perceived ability to solve family problems increases the likelihood to be selfless in handling family problems. Furthermore, worry and anxiety decreases the willingness to help family members but the goal of making their family members happy contributes to their desire to respond and prioritize their family's needs. The study strengthens and affirms the collectivistic culture and strong family ties of Filipinos.
\end{abstract}

\section{Keywords: Codependency, family functioning, personality type}

\section{INTRODUCTION}

Substance use problems affect not only the substance users but also the people involved in their social context, the codependents. Drug rehabilitation facilities or community-based rehabilitation programs primarily address the concerns and issues of the patients but not among the codependents. The facilities need to work closely not just with the patients but much more with the codependents who play a vital role in the recovery of the patients. The codependents deserve greater attention in the treatment programs which invite a great need to develop evidence-based programs.

In the actual setting of treatment and rehabilitation programs, the codependents undergo minimal programs and are more in need of measures that would help in the sobriety of the patients. Existing literature [1] identified lack of studies among codependents which further research investigating the factors involved in the development of programs for the codependents and clearly gave reason and need to conduct this present study [2].

Codependents are prone to other psychological problems and most likely experience codependency. Codependency is a dysfunctional relationship between two people characterized by over-functioning and being emotionally dependent to another person but under-functioning in their own life [3] [4]. It may be experienced by any codependents such as a child, spouse, or a parent of the patients [5] [6].

Self-neglect and low self-care are characteristics of codependency. The person's ability to sustain a healthy, meaningful, and fulfilling relationship is affected and may even lead to secondary issues such as anxiety and depression [7] The study of Manda [8] among codependents in a selected province in the Philippines suggests that $56 \%$ of codependents experience normal ups and downs, $17 \%$ are moderately depressed and 6\% are clinically depressed.

One of the factors considered to have correlation with codependency includes family functioning [7]. Family normally undergoes developmental changes in relation to the milestones experienced by the family member. The changes experienced by one member affects all the family member in one way or another. With all the changes and development going on, the family is the source and foundation of support, growth, and personal development of a person. Family plays a key role especially in health- 
related treatment disorders which includes codependency [9].

The study of Panaghi et al. [10] among wives of substance users or patients has shown that personality type was found related with codependency. Specifically, high neuroticism, low agreeableness, and low openness among wives predicts codependency. The high anxiety, worry, fear of neuroticism, low prosocial behavior of agreeableness and low creativity and capability of openness increase the likelihood of codependency. Taken these concepts and arguments into consideration, the present research sought to measure the determinants of codependency considering family functioning \& personality type.

\section{BACKGROUND}

The study utilized several theories as framework in the study. As for family functioning, the study used family functioning theory.

\subsection{Family functioning theory}

The family is the basic unit in the society. The relationship with each family member is important. The family systems theory posits that one experience of a family member affects the whole system of the family in terms of communication, boundaries, and emotional regulation. The cognitive-behavioral theory by Beck applied in family setting understands not only the family atmosphere or attitudes but the skills that family members possess in having a better family functioning. This family functioning includes problem solving, communication skills, and personal goals. Problem solving concerns the structured process of the family in solving problems using the six steps: identify the problem, list possible alternative solutions, discuss the positive and negative aspects of each option, choose the best, plan the solution, and check and review the implementation and planning [11].

In addition, the communication skills focus on the expression of positive and negative feelings, making of requests, and active listening with each family member. Moreover, the personal goals pertain to the capability of each family member to identify personal goals and maintain one's individuality with healthy boundaries. In other words, the three dimensions are important components of one's functioning as a member of the family system [11].

\subsection{Personality type theory}

The personality theory of McCrae and Costa focused on the five-factor model (FFM) of personality. These are openness to experience, conscientiousness, extraversion, agreeableness, and neuroticism. Openness to experience is characterized by seeking out different and varied experiences. Conscientiousness describes being organized, ambitious, and self-disciplined. Extraversion is described as sociable, talkative, fun loving, and affectionate. Agreeableness scale refers to being softhearted, trusting, generous, yielding, acceptant, and goodnatured. Neuroticism is described as worried and anxious [12]. The FFM has three central components which include basic tendencies, characteristic adaptations, and self-concept.

Personality highly considers the biological make-up of the person and the stability over time and situation. On the other hand, the flexibility of the person to adapt in circumstances is referred as characteristic adaptation. The characteristic adaptations are influenced by external influences such as the acquired skills, habits, attitudes, and relationships that result from the interaction of individuals with their environment. These two components are central tenets of FFM. The basic tendencies are stable and enduring; whereas, the characteristic adaptation fluctuates and subjects to change considering the environment. The self-concept pertains to the knowledge, views, and evaluations of the self which gives a sense of purpose and coherence in life. The interaction of these three components makes up the FFM [13].

\subsection{Codependency theory}

The present research utilized the conceptual framework of codependency by Cermak [14] which is the personality model of codependency. The personality model explains the role of personality and other constitutional factors in predisposing individuals to develop codependency.

Codependency is explained as being overly dependent on others, focusing on alleviating others' problem but ignoring one's personal needs. These are characterized in terms of external focus or focusing attention on the behavior, opinions, and expectations of others to gain approval or affection; self-sacrifice by neglecting one's own needs to focus on meeting the needs of others; reactivity or the belief in one's capacity to solve others' problems and control their behavior [11].

The family of the patient, the codependents are more prone to experience codependency. The whole family becomes chaotic and experiences destabilization caused by the substance use of the family member, the patient. The family tends to respond inappropriately to the problem caused by the substance user. The codependents may serve as enabler or someone who unconsciously or consciously tolerates the substance use of the patient. This relates to the family system model of addiction which indicates substance use problem as a family disease affecting not just the substance user but the whole family system as well [15].

\section{METHODS}

The population of the study are the family members or codependents of residents admitted in the public and private residential drug treatment rehabilitation programs in the Philippines. The respondents of the study are one of the residents' family who serve as the active immediate 
guardian of the resident. The 302 sample of the study was selected through purposive sampling technique. Purposive sampling technique is the gathering of data among samples who met the set criteria of the study. The inclusion criteria were: a member of the nuclear family of the resident (e.g., spouse, child, parent, sibling) otherwise, a current active guardian of the resident; currently enrolled in a treatment program either public or private; actively involved in the treatment process of the resident by having attended in at least one codependent meeting organized by the facility as verified by the facility; must have at least one month of involvement in the facility and that the resident must have been in the facility for at least one month. As for the exclusion criteria, the study did not include the codependent whose patient was not enrolled in residential facility treatment program either in public or private. In addition, patients who were not recovering from substance-related problems and were mainly diagnosed with mental illness such as depression, bipolar, and anxiety disorders were not included. In other words, those with no comorbidity of substance-related problems were excluded in the study.

Out of 302, there were $228(75.4 \%)$ from Luzon, 19 (6.2\%) from Visayas, and 48 (15.89\%) from Mindanao. As for the respondents' profile, 70 wives were involved, 63 mothers, 25 sons, 22 fathers, 13 daughters, and only eight husbands. There were 85 other members who were comprised of siblings, aunts, uncles, and grandparents. In terms of sex, 215 are female and 63 are male.

The respondents have taken three sets of questionnaires to measure the family functioning, personality type and codependency. Two of these were self-constructed while the personality type questionnaire was a standardized questionnaire. The two sets of self-constructed questionnaires were family functioning questionnaire (FFQ) and codependency questionnaire (CQ). The selfconstructed questionnaires underwent expert validation and reliability. The data collected were treated and analyzed using SPSS.

\section{FINDINGS \& DISCUSSIONS}

\subsection{Predictors of Codependency in Terms of Self-Sacrifice Using Family Functioning and Personality Type}

Table 1 presents the regression analyses of self-sacrifice. The result presents that problem solving skills is a predictor of self-sacrifice. The regression analysis shows that problem solving skills predicts self-sacrifice with the variance accounted for $13.6 \%$. This means that $13.6 \%$ of self-sacrifice is explained and contributed by problem solving skills.
Table 1 Regression analyses of self-sacrifice using Family Functioning and Personality Type

\begin{tabular}{llll}
\hline Predictor Variable & $\boldsymbol{B}$ & $\boldsymbol{t}$ & $\Delta \boldsymbol{R}^{2}$ \\
\hline Problem Solving Skills & .368 & 6.860 & .136 \\
\hline
\end{tabular}

$F=47.065 ; d f=300,1 ; p=.000 ; R^{2}=.136$

The result shows that the problem-solving skills of the respondents determine self-sacrifice. Further, it means that the respondents' ability to solve problems and provide accurate solutions to the concerns contribute to their willingness to prioritize others more than themselves. It explains that their conviction of their personal competencies and abilities in solving problems helps them respond to the needs of their family even at their own cost. The result implies that the codependents prioritize the needs of others more than their personal needs and that they address the demands of others over themselves as long as they have the ability to solve problems, evaluate solutions, and handle problems properly. On the other hand, the respondents are less likely to go extra-mile of helping if they do not have the skills and capabilities of evaluating the problems and choosing solutions to the problems. Similarly, Lancer [16] characterizes the codependents as being helpful and selfless just to address the concerns of others. In the process of helping, the family member experiences challenging problems and the skills of problem solving is necessary to better address the demands and needs of others appropriately. However, solving the problems of their dependents may most likely result into higher tendency for the codependents to be more sacrificial to others and would not be of help to the dependents instead. For instance, providing solutions to their problems may create more harm than good as the wrong doings of the dependents seem to be tolerated and not disciplined [17].

Beattie [18] argued the concept of codependents as enabler, which means that they tolerate the wrong behaviors of their dependents by taking the problems away from the dependents. The codependents face the challenges such as paying for the accidents, giving bail, and the like as caused by the dependents. These may do more harm than good to the dependents which invites for proper regulation of help to the dependents.

\subsection{Predictors of Codependency in Terms of Reactivity Using Family Functioning and Personality Type}

Table 2 presents the regression analyses of reactivity. The result shows that the reactivity of the respondents is contributed by problem solving skills, neuroticism, and goal setting. 
Table 2 Regression analyses of reactivity using family functioning and personality type

\begin{tabular}{llll}
\hline Predictor Variable & $\boldsymbol{B}$ & $\boldsymbol{t}$ & $\Delta \boldsymbol{R}^{2}$ \\
\hline Problem Solving Skills & .251 & 3.892 & .139 \\
Neuroticism & -.143 & -2.672 & .025 \\
Goal Setting & .173 & 2.665 & .020
\end{tabular}

$F=22.214 ; d f=296,3 ; p=.000 ; R^{2}=.184 ; R=.429$

The result means that problem solving skills, neuroticism, and goal setting predict reactivity with the variance accounted for $13.9 \%, 2.5 \%$, and $2.0 \%$, respectively. Of the predictor variables, problem solving skills have the highest variance accounted for which indicates that the respondents' capacity to solve problems determine their likelihood to respond and act as the "hero" in their family. The present findings imply that their ability to solve problems increases their likelihood to provide solutions beyond what is expected of them just to fix the problems of their family. In addition, as for neuroticism, the result means that the respondents' anxiety and worry lessen their willingness to solve their family problems.

Moreover, with regard to goal setting, the result indicates that the more the codependents have personal goals in their life, the more likely they are to provide help to their family and fix problems as soon as they come. The result suggests that problem-solving skills of the respondents are the highest predictor of reactivity. It is important to know the skills necessary to be able to solve problems properly.

According to Jakobsson, Ylven, and Moodley [19], emotional stability, maturity and analytical processes constitute problem solving skills. The way the person handles the challenge and how they perceive the problem play important role in problem solving. However, the problem-solving skills of a person varies from one person to another considering the content and emotional relevance of the problem. Specifically, the parent-child relationship which pertains to the emotional closeness and attachment of the mother to a child and vice versa.

In relation to the present findings about neuroticism as a predictor, Ackerman [20] found that neuroticism is generally linked to poorer performance. His study implies that the higher the anxiety, the less likely that the person will be productive in life. This is related to the present findings in which high neuroticism lessens the willingness of the respondents to respond and fix the problem of the dependent. The characteristics of neuroticism such as anxiety, sadness, worry, pessimism, emotional stability, and general temper hampers the ability of the codependent to fix and resolve the concerns of the family.

\subsection{Predictors of Codependency in Terms of External Focus Using Family Functioning and Personality Type}

Table 3 presents the regression analyses of external focus. The result shows that goal setting, agreeableness, and problem-solving skills predict external focus with the variance accounted for $16.8 \%, 2.4 \%$, and $1.5 \%$, respectively.

Goal setting has the highest variance accounted for which means that the goals set by the codependents for themselves in relation to their family's goals contribute to their level of external focus. The findings imply that the codependents' being goal-oriented is a factor which contributes to their willingness to prioritize their family over their own needs. In other words, it is the codependents' desire to make their family happy and to receive approval from them because it is their personal goals in life.

Table 3 Regression analyses of external focus

\begin{tabular}{llll}
\hline Predictor Variable & $\boldsymbol{B}$ & $\boldsymbol{t}$ & $\boldsymbol{\Delta} \boldsymbol{R}^{\mathbf{2}}$ \\
\hline Goal Setting & .298 & 4.702 & .168 \\
Agreeableness & .140 & 2.638 & .024 \\
Problem Solving Skills & .149 & 2.334 & .015 \\
\hline
\end{tabular}

$F=25.855 ; d f=298,3 ; p=.000 ; R^{2}=.207 ; R=.454$

Furthermore, the results show that agreeableness also predicts external focus which means that their trait of being helpful and altruistic determined their being occupied in pleasing their family to be happy. Also, the result shows that problem solving skills predict external focus which indicates that the codependents' ability to solve problems contributes to their high consideration of their family's feelings and wants.

In relation to the present findings regarding goal setting as a predictor of external focus, the study of Pe-Pua and Marcelino [21] argued that Filipinos consider the family's welfare as one of their personal goals. For instance, the Filipino value of utang na loob may explain the present findings in which the codependents include their loved one's happiness as part of their goal in life. They value the family ties, and they want to express their gratitude/solidarity by returning the favor to them. They comply to the requests of their loved ones as much as they can.

Agreeableness is also shown as a predictor of external focus. The agreeable characteristic of a person is expected to be a predictor of external focus. According to Campbell and Graziano [22], agreeable individuals are constructive and practice prosocial thoughts and behaviors in addressing aggressive and hostile circumstances. They manage their emotions so as not to hurt others' feelings. They are willing to compromise to remain cool and calm regardless of the situation they are in. The focus of agreeable individuals is to keep one's emotion intact, to 
address conflict constructively, and to be in good relationship with others [23]. These characteristics help explain agreeableness as a predictor of external focus.

The social problem-solving theory supports the present findings of the study which show that problem solving skills predict external focus. The theory suggests that emotion, maturity, and analytical processes constitute problem solving. One's emotional stability, mature way of handling challenges, and how the problem is perceived play important roles in problem solving. This means that the skills of a family member vary from one member to another considering the emotional maturity and analytical process of the person. In addition, the possibility of solving a problem may vary depending on the content and emotional relevance of the problem. Take for instance the parent-child relationship which explains the problemsolving skills especially those of mothers as a predictor of external focus [19].

\section{CONCLUSION}

The study strengthens one of the Filipino values which is strong family ties. Specifically, those family members with high belief of their capacity to solve family problems tend to be more helpful to handle conflicts \& challenges especially to their recovering family member. On the other hand, being anxious of their capacity to help makes them less responsive in solving family members. Moreover, the study concludes that making the family members happy and in good condition is their goal in life which indicate that the well-being of the family is their utmost priority though it takes sacrifice on their part.

\section{ACKNOWLEDGMENT}

This work was funded by Institute of Research $\&$ Community Engagement. The researchers are grateful to the Faculty of Psychology, Universitas Tarumanagara especially to the Dean of Psychology who has given the support for this International-Collaboration Research.

\section{REFERENCES}

[1] I. Bacon, E. McKay, F. Reynolds, \& A. McIntyre, The lived experience of Codependency: An interpretative phenomenological analysis, in: International Journal of Mental Health and Addiction, 2018, pp. 1-18. DOI: https: //doi:10.1007/s11469-0189983-8

[2] C. Bortolon, L. Signor, T. Moreira, L. Figueiro, M. Benchaya, C. Machado, M. Ferigolo, H. Barros, Family functioning and health issues associated with codependency in families of drug users, in: Ciencia \& Saude Coletiva, 2014, pp. 101-107. DOI: https://doi: 10.1590/141381232015211.20662014.

[3] A. Manda, Codependents of recovering addicts: Exploring their level of depression and self-esteem, in: Asia Pacific Journal of Multidisciplinary Research, 2(2), 2014, 66-72.

[4] M. Rusnakova, Codependency of the members of a family of an alcoholic addict, in:Procedia Social and Behavioral Sciences, (132) 2014, 647-653.

[5] L. Dessauer, Are you raising a codependent child? Codependent child no more, in: Psychology Today, (08) 2011.

[6] R. Lohmann, Codependency in children, in: Psychology Today, (10) 2013.

[7] N. Bell, Know your attachment style and overcome dependency, in: Counseling Directory, 2017.

[8] A. Manda, Codependents of recovering addicts: Exploring their level of depression and self-esteem, in: Asia Pacific Journal of Multidisciplinary Research, 2 (2), 2014, 66-72

[9] C.B. Borton, M. Ferigolo, H. Barros, Families that live with disorders related to substances and addiction, in: Journal of Drug Abuse, 3 (1), (2017) pp. 1-4.

[10] L. Panaghi, Z. Ahmadabadi, N. Khosravi, M. Sadeghi, A. Madanipour, Living with addicted men and codependency: The moderating effect of personality traits, in: Addict Health, 8(2), (2016) 98-105.

[11] R. Roncone, M. Mazza, D. Ussorio, R. Pollice, I. Fallon, P. Morosini, M. Cassachia, The questionnaire of family functioning: A preliminary validation of a standardized instrument to evaluate Psychoeducational Family Treatments, in: Community Mental Health Journal, 43 (6) (2007) 591-608.

[12] D. Schultz, S. Schultz, Theories of personality, Cengage Learning, California, USA, 2013.

[13] J. Feist, G. Feist, Theories of Personality, 7th ed. McGraw Hill, USA, 2008

[14] T. L. Cermak, Diagnosing and treating codependence. Johnson Institute, Minneapolis, 1986.

[15] O. Curtis, Chemical dependency: A family affair, Brooks/Cole Publishing Company, Pacific Grove, California, 1999. 
[16] D. Lancer, Symptoms of codependency, What is Codependency, 2018.

[17] R. Lee, Codependency: The helping problem, in: Psychology Central, 2018.

[18] M. Beattie, Codependent no more: How to stop controlling others and start caring for yourself, Hazelden, Center City, MN, 1992.

[19] E. Jakobsson, R. Ylven, L. Moodley, Problem solving and positive family functioning: Some reflections on the literature from a cross cultural point of view, in: South African Journal of Occupational Therapy, 2007, 14-16.

[20] C. Ackerman, Big five personality traits and the 5Factor model explained, in: Positive Psychology Program, 2017.

[21] R. Pe-Pua, E. Marcelino, Sikilohiyang Pilipino (Filipino psychology): A legacy of Virgilio G. Enriquez, in: Asian Journal of Social Psychology, 3, 2000, pp. 49-71.

[22] L. Campbell, W. Graziano, Agreeableness as a moderator of interpersonal conflict, in: Journal of Personality, 69(2), (2012), 323-362.

[23] M. Robinson, The power of agreeableness, in: Association for Psychological Science $24^{\text {th }}$ Annual Convention, 2012. 